\title{
The views of singlehanded general practitioners: a qualitative study
}

\author{
Judith M Green
}

\begin{abstract}
Objectives-To examine the concerns of singlehanded general practitioners working in an inner London area and to compare the views of general practitioners in partnerships.

Design-Qualitative analysis of semistructured interviews with a random sample of singlehanded general practitioners and a sample of general practitioners from partnerships matched for age and sex.

Setting-The area covered by Lambeth, Southwark, and Lewisham Family Health Services Authority.

Results-The singlehanded general practitioners were more likely to be older, male, and first qualified abroad than general practitioners in partnerships. Their major concerns were inadequate premises, maintaining their singlehanded status, and coping with recent changes to their contract. Most were very satisfied with their solo status and did not see the provision of 24 hour care as stressful.

Conclusion-Singlehanded general practitioners saw themselves as providing a unique service for patients, and their status as an alternative for general practitioners who were unhappy in partnerships. Such practices are unlikely to wither away as a pattern of provision. Any comprehensive development of primary care must take their needs into account.
\end{abstract}

\section{Introduction}

Nationally $11.6 \%$ of general practitioners work as the sole principal in their practice, ${ }^{1}$ although in London the proportion is higher-for example in the area covered by Lambeth, Southwark, and Lewisham Family Health Services Authority 19\% of all general practitioners are singlehanded. These general practitioners have been characterised as a "problem": they have been associated with inadequate premises, poor out of hours cover, an inability to practise within an integrated primary care team, and with being less likely to be members of professional associations, ${ }^{2-4}$ although the patients of singlehanded general practitioners report that they are as satisfied with their doctor as are patients of larger practices. ${ }^{4}$

More recently there have been indications that singlehanded general practitioners may have been disadvantaged by the terms of the new contract, given their relative inability to meet the criteria deemed necessary to provide minor surgery ${ }^{5}$ and their lack of resources, staff, or list size necessary to provide health promotion clinics. They cover considerably more weekday nights and weekends on call (a major potential source of stress ${ }^{6}$ ) than those with partners.?

Despite the identification of singlehanded general practitioners as "a cause for concern" in most of the existing literature ${ }^{8}$ there has been little research directly addressing their needs. In the light of debate following the Tomlinson inquiry about the future of
London's primary health service ${ }^{9}$ it seemed timely to examine the motivations, problems, and concerns of singlehanded general practitioners. The aim of this qualitative study was to look at the views of singlehanded general practitioners in one inner city area, that covered by Lambeth, Southwark and Lewisham Family Health Services Authority.

\section{Methods}

General practitioners working in the Lambeth, Southwark, and Lewisham area were divided into two groups: those who were singlehanded principals and those who had partners. Twenty five general practitioners were randomly selected from the list of singlehanded general practitioners and invited to take part in a semistructured interview. The agenda for the interview was in part set by the general practitioners themselves, who were initially asked about how they became singlehanded, the satisfactions and problems of working as singlehanded practitioners, and their attitudes to the new contract.

A further 25 general practitioners were systematically sampled from the group with partners to reflect the age and sex distribution of the random sample of singlehanded general practitioners. Interviews with this group were more directed so as to cover the issues raised by the singlehanded general practitioners.

Interviews were carried out between August 1992 and February 1993. All but two of the singlehanded group and two of the partners group agreed to the interview being audio taped. Tape transcripts and notes from other interviews were then analysed by using qualitative methods: generating categories of concerns through line by line analysis of transcripts, ranking concerns according to their salience for respondents, and coding the transcripts to enable the occurrence of themes to be quantified. Such analysis allows a more in depth description of social phenomena than quantitative methods and permits the concerns of the participants rather than the researcher to emerge..$^{10}$ Given that much of the comment on singlehanded general practitioners has assumed that they are a problem in relation to the ideal of group practice, it was thought important to adopt a methodology which allowed the agendas of singlehanded general practitioners themselves to be elicited. ${ }^{11}$ The value of such methods has been shown recently by work on issues as diverse as sudden infant death syndrome and hospital waiting lists. ${ }^{12} 13$

\section{Results}

\section{THE POPULATION}

Eighty one (19\%) of the 425 general practitioners on the family health services authority's list were working as the only principal in the practice. They were more likely to be male and to have qualified outside Britain and were on average older than the partners (table I). If those who qualified since 1981 were excluded (as their the SETRHA Primary Care Development Fund. 
TABLE I-Characteristics of singlehanded general practitioners and those from other practices. Values are numbers (percentage) of general practitioners ${ }^{\star}$

\begin{tabular}{lccc}
\hline & \multicolumn{3}{c}{ Practice size } \\
\cline { 2 - 4 } & Singlehanded & With partner(s) & All \\
\hline Sex: & & & \\
$\quad$ Female & $10(12 \cdot 5)$ & $129(38 \cdot 6)$ & $139(33 \cdot 6)$ \\
$\quad$ Male & $70(87 \cdot 5)$ & $205(61 \cdot 4)$ & $275(66 \cdot 4)$ \\
$\quad$ All & $80(100)$ & $334(100)$ & $414(100)$ \\
Country of qualification: & $35(43 \cdot 2)$ & $264(79 \cdot 3)$ & $299(72 \cdot 2)$ \\
$\quad$ Britain & $46(56 \cdot 8)$ & $69(20 \cdot 7)$ & $115(27 \cdot 7)$ \\
$\quad$ Elsewhere & $81(100)$ & $333(100)$ & $414(100)$ \\
All & & $19 \cdot 6$ & $21 \cdot 2$ \\
Mean number of years since & 28.0 & & \\
$\quad$ qualification & & &
\end{tabular}

${ }^{\star} \mathrm{N}=425$ general practitioners in total. Table does not include missing data.

inexperience would probably disqualify them from taking on a singlehanded practice) the mean length of experience of the singlehanded general practitioners was 28 and of the others was 23 years (Mann-Whitney $\mathrm{U}$ test $=6888 \cdot 0, \mathrm{p}<0 \cdot 0001)$.

THE SAMPLES

All 25 singlehanded general practitioners sampled agreed to be interviewed. One of the partners sampled declined, leaving 24 in the comparison group. The singlehanded group included four women and 21 men. Twelve of the singlehanded general practitioners had qualified in Britain, 13 elsewhere. Of the partners, who had been chosen to reflect the age and sex distribution of singlehanded general practitioners, 16 had qualified in Britain and eight elsewhere.

\section{BECOMING AND STAYING SINGLEHANDED}

None of the singlehanded general practitioners interviewed had intended at the beginning of their careers in general practice to work alone, and all but three had worked in partnerships at some time. Eleven of them described their singlehanded status as the result of an active decision to work alone, a further 11 reported that it had just happened that way, and the remaining three were unclear as to the extent to which it had been actively chosen. The most common reason for making the decision was a negative experience of partnerships, rather than a positive desire to work alone, and many of those interviewed had stories to relate about partnerships which had not worked. Problems were perceived as arising from differences in attitudes to responsibilities and remuneration, and exploitation of junior partners. As one said, "All those in the group weren't pulling their own weight. And

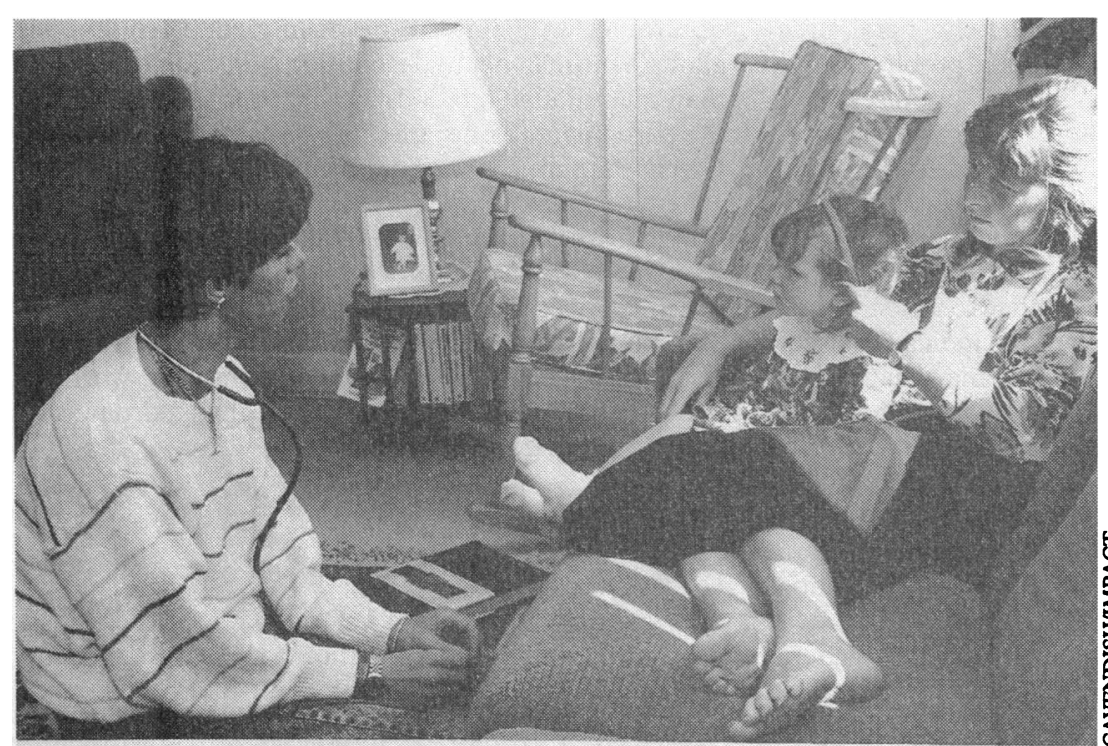

The meaning of "out of hours" becomes different in the context of the doctor's membership in the local community, with a discrete list of patients being a junior, I was doing most of the work and they were getting away with it."

Having ended up working alone the majority (16) of the singlehanded general practitioners were unreservedly satisfied with their status, and only two reported themselves as dissatisfied overall. They cited their ability to organise their own workload ("you are your own boss") and the lack of conflicts, which had for many of them characterised partnerships, as the major sources of this satisfaction.

Nine of the partners had at some point in their career been singlehanded. None of them reported that they would currently prefer to work as a singlehanded practitioner, citing team working and the clinical, practical, and emotional support of other doctors as the major incentives for remaining in partnerships. Professional isolation and difficulties of providing 24 hour cover for patients were seen as the major disincentives to singlehanded practice.

\section{PROBLEMS}

The singlehanded general practitioners were less likely to be working from purpose built premises, have a practice nurse, or offer health promotion clinics (table II). The lack of adequate premises was of concern to most of the singlehanded general practitioners interviewed, occasionally to the exclusion of all other concerns. Fewer of them worked from purpose built premises than the partners sampled, but purpose built did not necessarily equate with adequacy. Two of the singlehanded general practitioners worked in health centres but found their accommodation cramped and presenting particular problems such as differences of opinion with other users of the health centre over common resources. Non-purpose built accommodation could suit the idiosyncratic style of some of the singlehanded general practitioners, and one doctor mentioned that consulting in the family home had been an advantage while her children were small.

TABLE II-Number of general practitioners with purpose built premises, practice nurse(s), and health promotion clinics

\begin{tabular}{lcc}
\hline & $\begin{array}{c}\text { Singlehanded } \\
(\mathbf{n}=25)\end{array}$ & $\begin{array}{c}\text { With partner(8) } \\
(\mathbf{n}=24)\end{array}$ \\
\hline With practice nurse(s) & 9 & 20 \\
Run health promotion clinics & 8 & 22 \\
Purpose built premises & 8 & 15 \\
\hline
\end{tabular}

Seven singlehanded general practitioners mentioned problems with finding locum cover: one claimed not to have had a holiday for nine years. There were practical problems in finding reliable locums and in coping financially, but some of the singlehanded doctors also felt unhappy about leaving "their" practice in the hands of someone else. This reluctance was extended to out of hours cover, with five of the singlehanded doctors reporting providing 24 hour cover themselves every day and a further four reporting being on call until at least $11 \mathrm{pm}$ every night.

\section{THE SPECIAL RELATIONSHIP}

Four singlehanded general practitioners reported finding sole responsibility for patients a stress but it was more often talked about as a satisfaction, which arose from the special relationship which they claimed to enjoy with their patients, who enjoyed continuity of care, sometimes over several generations. Although the partners also thought their relationships with patients were important, they did not mention this factor so often unprompted and did not report it so often as essential in high quality primary care. Only five of the partners said that they strongly encouraged patients to see the same doctor at every visit. 
The singlehanded doctors made many references to the geographical community within which they practised, claiming that the general practitioner's job was to be available and to understand the needs of the local community. The partners were more likely to emphasise the negative aspects of their catchment area: the dangers of doing night calls on estates, or the high levels of deprivation. They were also more likely to identify with a professional community than a local one, and some felt that the lack of a professional community would be an isolating feature of singlehanded practice: "I think the worst of the problems for singlehanded practitioners is the lack of ability to explode about patients to each other."

The special relationship enjoyed by singlehanded doctors was seen by both groups of doctors as an anachronistic one; but for the singlehanded doctors it still existed ("I'm a doctor of the '50s-with a little bit of charm, a little bit of courtesy, and very good manners") whereas the partners tended to see it as characterising a bygone age of general practice. For the singlehanded doctors the doctor-patient relationship was still the bedrock of good general practice.

\section{COPING WITH CHANGE}

Although few respondents raised the 1991 new contract unprompted as a cause for concern, it was attitudes to the recent changes that differed most explicitly between the partners and the singlehanded doctors. This was related to attitudes to the family health services authority, which was responsible for implementing the new terms of their contract. Eight of the singlehanded general practitioners made only negative comments, compared with three of the partners. Two of the singlehanded general practitioners felt that the family health services authority was overtly prejudiced against singlehanded practices in terms of how cost-rent and staff reimbursements were awarded.

None of the doctors interviewed were completely positive about the changes, but seven of the partners had an approach that they described as being able to "take advantage of the rules, seeing change as a challenge" or "play the systems so that we are winners." None of the singlehanded general practitioners reported such views, and they were more fatalistic about their ability to adapt to the changes brought by the new contract. They described health promotion clinics as not only difficult to organise with a smaller list than that of a large partnership ("I would be wasting my time waiting for 10 patients") but also as contrary to the demand led style in which they practised: "You get just as good results, you know, from when they feel ill enough to come." The organisation entailed in running clinics was seen as a potential interference with the close relationship between doctor and patient: "I don't want to treat a whole lot of anonymous individuals who are lining up outside."

In providing primary care for a defined group of patients they knew well, the singlehanded doctors recognised that there were limitations in the range of services they could provide. Whereas the partners cited the range of skills and resources they could offer as their advantage for patients, many of the singlehanded doctors noted that there were specific kinds of patients that they could not cater for ("Most people who come here don't expect babies and so on"; "I tell them, 'If you join here, I don't have any support services'"). For those patients who did join the list, though, the small scale meant that the doctor would know the patient in enough depth not to need clinics, which the singlehanders saw as contributing to the "busy, frenetic atmosphere" of the health centre that their patients were deliberately rejecting.

\section{Discussion}

This study examined the concerns of a random sample of singlehanded general practitioners in one inner London area and compared them with those of a group of partners of similar age. It is not possible to comment on how representative they may be of singlehanded general practitioners in other parts of the country, although some of the views expressed in this sample accord with concerns noted in other studies. ${ }^{1416}$

The population of singlehanded general practitioners was a fluid one, with several doctors on the family health services authority's list joining or leaving singlehanded practice during the period of the study. Most of the singlehanded doctors interviewed had at some time in their career worked in partnerships, and some of the partners had worked singlehanded. Despite this apparent arbitrariness, there were some features that seemed to characterise the group of singlehanded general practitioners. These features perhaps relate to a different style of practice rather than necessarily different behaviours or attitudes. Some aspects of this style can be operationalised and quantified, such as whether health promotion clinics were organised or whether attitudes to the family health services authority were positive or not, but others are more elusive. The qualitative approach of this study allowed the main concerns of singlehanded general practitioners to emerge in the context of how they see general practice rather than assuming the conventional view of the shortcomings of singlehanded practice. There are potentially positive aspects to providing care in this form. The singlehanded general practitioner may know his or her population in considerable depth ${ }^{14}$ and may be able to provide the kind of continuing and personal care that is still important to patients ${ }^{1516}$ and which may be difficult to provide in larger practices. ${ }^{17}$

Their major concerns were not those assumed by their colleagues from larger practices or in many reports. Professional isolation was not experienced as a loss but rather as a benefit. It brought a closer identification with the patient community and a depth of relationships that could not be achieved by doctors working in larger practices. Although finding reliable cover for holidays and other absences was perceived as a problem, singlehanded general practitioners took pride in coping on their own and felt that their position as "the doctor" to a discrete list of patients was a privileged one providing a particular quality to their relationships with patients, a quality which had all but disappeared in other parts of general practice. Although their descriptions of this special relationship and of the

\section{Practice implications}

- Much of the literature on primary care assumes that singlehanded general practitioners are "a problem"

- This study found that singlehanded general practitioners were satisfied with their status and did not want to join partnerships

- General practitioners felt that there were important advantages for patients in the continuity and detailed knowledge of the community that singlehanded general practitioners could provide

- Singlehanded practice provides an alternative for general practitioners who are not suited to team working

- Any comprehensive development of primary care requires support for singlehanded general practitioners, not discouragement 
local community may have the flavour of rhetoric rather than objective description, they are perhaps important as statements about what general practice should be. The singlehanded general practitioners were providing a service that was seen by many respondents to belong to an older age of general practice, when there were perhaps fewer services that could be offered to patients, and when the doctor was a member of the local community rather than a professional coming to work in it for a contracted number of hours. The meaning of "out of hours" becomes very different in this context, and consequently the singlehanded doctors reported less dissatisfaction than might be expected from their workload.

The career histories told by singlehanded general practitioners, many of whom were refugees from partnerships, suggest that there may be a need for this kind of practice, both for those doctors who do not want to work within a team and for patients who prefer the smaller scale of the singlehanded practice. These doctors were satisfied with their singlehanded status and had no desire to join with larger practices or even share out of hours rotas with them. This, and their reluctance to run health promotion clinics, perhaps resulted as much from their different approach to primary care as it did from the practical constraints of their position. This has important consequences for London family health authorities attempting to change the behaviour of general practitioners in their areas in line with the recommendations of Tomlinson. ${ }^{9}$

This study has suggested some reasons why the heralded demise of singlehanded practice has not occurred. It may now be time to assume that an appreciable proportion of London's population will continue to be cared for by singlehanded doctors and to identify ways of supporting those general practitioners in their provision of good primary care, rather than merely encouraging partnerships as the undisputed ideal of modern primary care.

This study was funded by the SETRHA Primary Care Development Fund. I thank Wayne Parkin, Beryl Stevens, and Natasha Yamin, who transcribed the audio tapes. I am grateful to Professor David Morrell, Ms Clare Jenkins, Dr L Alan Ruben, and Lambeth, Southwark, and Lewisham Family Health Services Authority for providing information, advice, or support and to Dr David Armstrong for his advice throughout the study and comments on an earlier draft of this paper. Most importantly, I am grateful to the general practitioners who took time to talk to me.

1 Department of Health. Health and personal social service statistics for England. London: HMSO, 1992

2 London Health Planning Consortium. Primary health care in inner London. London: London Health Planning Consortium, 1981. (Acheson report.)

3 Morley V, Evans T, Higgs R, Lock P. A case study in developing primary care. London: King's Fund Centre, 1991.

4 Cartwright A, Anderson R. General practice revisited: a second study of patients and their doctors. London: Tavistock Publications, 1981.

5 Zoltie N, Hoult G. Adequacy of general practitioners' premises for minor surgery. $B M F$ 1991;302:941-2.

6 Makin P, Rout U, Cooper C. Job satisfaction and occupational stress among general practitioners-a pilot study. $¥ R$ Coll Gen Pract 1988;38:303-6.

7 ERBS (Electorial Reform Society). Your choices for the future: $a$ survey of GP opinion. London: The Society, 1991.

8 Fry J. Present state and future needs in general practice. Lancaster: MTP, 1983.

9 Tomlinson B, Bond M, Brown P, McBride M. Report of the inquiry into London's health service, medical education and research. London: HMSO, 1992

10 Strauss A. Qualitative analysis for social scientists. Cambridge: Cambridge University Press, 1987.

11 Murphy E, Mattson B. Qualitative research and family practice: a marriage made in heaven? Family Practice 1992;9:85-91.

12 Gantley M, Davies DP, Murcott A. Sudden infant death syndrome: links with infant care practices. $B M \mathcal{F}$ 1993;306:16-20.

13 Pope $C$. Trouble in store: some thoughts on the management of waiting lists. Sociology of Health and Illness 1991;13:193-212.

14 Wilkin D, Hallam L, Levey R, Metcalfe D. Anatomy of urban general practice. London: Tavistock Publications, 1987.

15 Bain J. General practice and the new contract. I. Reactions and impact. $B M \mathcal{F}$ 1991;302:1183-6.

16 Williams S, Calnan M. Key determinants of consumer satisfaction with general practice. Family Practice 1991;8:237-42.

17 Keeley D. Personal care or the polyclinic? BMf 1991;302:1514-6.

\section{A PATIENT WHO CHANGED MY PRACTICE}

\section{Asian rickets and osteomalacia}

As a senior house officer in Glasgow Royal Infirmary with a recently acquired membership qualification I realised that further progress to consultant status depended on my publications, even if, in the words of Lucky Jim, these shed only "pseudo-light on non-problems." In 1961, while struggling to produce several unmemorable papers in my then chosen specialty of haematology, Paul Paton, a consultant in our unit, asked me to see an Asian girl he had admitted with pains in her legs and difficulty in walking. Qulsoom was an apprehensive 13 year old with the gross deformities of knock kneed rickets. The diagnosis of active rickets was confirmed biochemically and radiologically; subsequent investigations showed similar deformities and active rickets in her sister and severe osteomalacia in her mother. No underlying reason for active rickets emerged in either girl and calcium balance studies showed a rapid response to a small oral dose of vitamin $D$. Moreover, the age of onset and nature of the rachitic deformity were quite unlike the typical deformities of infantile rickets which had made Glasgow the rickets capital of the world earlier in the century.

The first clue was provided by $\mathrm{Mr}$ F K Awan, a friend of the patient's family, who taught at a Gorbals primary school. He told me that many Pakistani children could not run, play games, or do physical education because of limb pains. Alec Brown, my then chief, persuaded our board of management to hire taxis to bring 12 children to the unit; all had biochemical evidence of rickets and several had obvious rachitic deformity. A fleet of taxis then brought in 74 members of the children's 11 families. Sixty four per cent of the adults and children who provided blood samples showed biochemical evidence of rickets or osteomalacia. I realised that I had stumbled on a major problem, and the published results marked the recognition in Britain of what was subsequently termed Asian rickets and osteomalacia. ${ }^{1}$ I thought that this was clinically relevant research.

In 1983 when I was engaged with my research dietitian, Janet Henderson, on further seven day measurements of the dietary intake and outdoor exposure of Glasgow Asian women ${ }^{2}$ I unexpectedly encountered Qulsoom as a 35 year old married housewife with two children. After reviewing the records of her week's weighing and outdoor exposure, we discussed her admission to the Royal Infirmary 22 years before, her bilateral osteotomy, and her further story. She had entered my life as the first documented case of Asian late rickets in Britain. She changed my cynical view that for most doctors research was a necessary chore which had to be endured to climb the promotion ladder. Instead, I learnt that clinically oriented research could be exciting and relevant, even with limited resources. After an afternoon of mutual reminiscences, tea, and a commemorative photograph, Janet and I left Qulsoom and her family in peace. I did not tell her how much she had changed my life.-MATTHEw DUNNIGAN is a consultant physician in Glasgow

1 Dunnigan MG, Paton JPJ, Haase S, McNicol GW, Gardner MD, Smith CM. Late rickets and osteomalacia in the Pakistani community in Glasgow. Scott Med f 1962;7:159-67.

2 Henderson JB, Dunnigan MG, McIntosh WB, Abdul-Motaal AA, Hole D. Asian osteomalacia is determined by dietary factors when exposure to ustraviolet radiation is restricted; a risk-factor model. $Q 9$ Med 1990;76: ultraviolet

We are delighted to receive submissions of up to 600 words on $A$ paper (or patient or book) that changed my practice, $A$ memorable patient, The one message I would like to leave behind, or related topics. 